\title{
Solving the Problem of Minimizing the Total Cost in the Integrated Planning of Production and Distribution in a Supply Chain Using Meta-Heuristic Algorithm
}

\author{
Hadi Pazoki Toroudi \\ Young Researchers and Elite Club, Qaemshahr Branch \\ Islamic Azad University, Qaemshahr, Iran \\ E-mail: h.pazoki.ums@gmail.com \\ Mahsa Sadat Madani \\ Department of Industrial Engineering, Tajan University, Qaemshahr, Iran \\ E-mail:mahsamadani94@gmail.com \\ Fatemeh Sarlak \\ Department of Industrial Engineering, College of Engineering \\ University of Tehran, Tehran, Iran \\ E-mail: Fateme_sarlak@yahoo.com \\ Yosef GholipourKanani \\ Department of Industrial Engineering, Qaemshahr branch \\ Islamic Azad University, Qaemshahr, Iran \\ E-mail: gholipourkanani@yahoo.com
}

Received: Nov. 2, 2016

doi:10.5296/jmr.v9i1.10591
Accepted: Dec. 30, 2016 Published: January 10, 2017

URL: http://dx.doi.org/10.5296/jmr.v9i1.10591 


\section{Abstract}

In this paper, a concurrent planning of production and distribution is considered for manufacturers. In the production section production machines with a specific capacity that has the possibility of process multiple tasks simultaneously are intended and the tasks have the desired size and processing time and the overall size of the tasks within each category does not exceed the capacity of the machine. Also in distribution section the vehicles have specified capacity. In this study, by using meta-heuristic Genetics Algorithm the production problem is solved and in genetic algorithms to obtain better solutions help operators crossover and mutation has been taken. Results show that by increasing the size of the issue of genetic algorithms nearly optimum solutions and provides a shorter running time.

Keywords: Integrated Planning, Production and Distribution Systems, Genetic Algorithms 


\section{Introduction}

In recent years the same time planning of production and distribution issue has gained importance among researchers. In these issues contrary to the classical problems of planning that pay attention only to the production, an inventory includes distribution and other parts of the production chain .The aim of the same time planning creates an optimal solution for the entire chain production. This study aims to solve the problem of production and distribution planning Ba-Yi Cheng, Joseph Y. T. Leung Kai Li in 2014 [1] has been investigated by genetic algorithms. In the section of the production of manufactured cars are considered with batch processing and are works with arbitrary size and processing time. This type of production is used in the semiconductor and Tile making industry [1]. The processing time of each category is equal to the time processing of all tasks within that category.

In the distribution section, the number of vehicles is available with fixed capacity it is desirable to minimize distribution costs that the number of vehicles minimized. A contemporary planning method is required for achieving the answer the optimal production and distribution issue. The aim of this article is to provide a way to solve this problem. The genetic algorithms have been used to categorize things in the production and distribution issue. Our goal is to minimize the costs of production and distribution.

\section{Subject literature}

Subject literature to the contemporary planning issues is very widespread and numerous studies have been done since the first studies in this field Jula, P. \& Leachman [2] and Selvarajah and Steiner [3] provided an approximation algorithm for minimizing the cost of holding inventory and delivering in three parts supplier, manufacturer, and customers. Sawik[4] expanded the issue for a long-term production. Yimer, A. D. Demirli [5] proposed dividing techniques for the issue. They divided the issue into two parts production and distribution and genetic algorithms to solve the model.

The two-part contemporary planning issue is two kinds, one type the related program suppliers and manufacturers and other is related to producers and customers. Chen and Vairaktarakis[6] showed that most of the two-part issues are NP-HARD. Chen and Hall [7] considered the middle of the optimization program supplier and manufacturer and presented a contemporary method for both two-part. Turabi, Qomi, and Karimi [8] stated average minimizing issue of maintenance cost of treatment and delivery cost in the supply chain and designed clever algorithm for it. Another type of the two-part issue is timing between producers and customers Agnetis, A., Aloulou and $\mathrm{Fu}$ [9] investigated the timing of contemporary produce and delivery of the package with considering an outside organization logistics. Algorithms for solving this issue are those that investigated by Averbakh, I. \& Xue, Z estimation theory and intelligent algorithm by Carter, C. B. and Norton [11] and Naso, D., Surico, M., Turchaiano, B. \& Kaymak, U. [12].

Chen and et al [13] provided a comprehensive and complete model of concurrent time production and distribution. Current studies focus on the classical models that produced at the same time the machine at any moment a piece focused processes. Few studies in the field of 
production models with batch processing machines and work has been done with the desired size and unlike the classic models produced the higher complexity of solving problems. Yvzsy [14] provides the numerous innovative models for single-machine scheduling problems. Models with a better performance single machine to solve problem was presented by Kashani, Karimi and Qomi [15] and Li, Wang and Liu [16]. Intelligent algorithms including genetic algorithm (Sevaux, press [17]; Koh, Kim and each [18]; temperature profile in, Mnjshvar and Sryhary [19]; Kashani, Karimi and HE [20]), simulated annealing (Maluku [21] ) and ant colony optimization (Cheng, Wang, Yang and $\mathrm{Hu}$ [22]) have been used to solve problems.

\section{The formulation of the issue}

Timing issue can be represented as follows:

There are the number of $\mathrm{n}$ enterprises for processing and delivery to the customer. $\tau=\{1,2, \ldots, n\}$ Indicate a set of tasks. $S_{j}$ Indicates the size of the portfolio and $t_{j}$ is indicative of the time of the $\mathrm{j}$ task processing time. Tasks are grouped into categories to go on batch processing machines. $\mathrm{B}$ is the capacity of the machine in fact tasks can be processed simultaneously on the condition that the total size of the portfolio does not exceed the capacity of the machine. Processing batches $k_{\text {show by }} b_{k}$ and will not be stopped until all the tasks process and the time of category $k$ that show with $T_{k}$ that is equal to the time processing of the longest task in that category $b_{k}$ and the completion time shows $C_{k}$ with and $C_{0}$ consider equal to 0 . Some of the categories are empty and the task does not assign to them which in this case processing time is zero and we have $T_{0}=0$. The number of non-empty categories shows with K. Given the plethora of working groups of the cost of production is a linear function of time:

$$
P C=\sum_{K=1}^{N} T_{k}
$$

When the works were completed, they can be delivered to customers. To simplify the issue, the amount of tasks in the production and distribution consider equal to each other. Vehicles have a common capacity $\mathrm{G}$ and products can be delivered in one shipment, provided that the size distribution of all the products available in cargo not exceed to capacity. And show the trustee of the Delivered collection and like production categories, some of the shipments may be empty and do not carry the task and $D=\left\{d_{1}, d_{2}, \ldots, d_{n}\right\}$ shows the number of non-empty deliveries that we define distribution costs that are a linear function of when each distribution in operation has similar costs. The objective function is to minimize the cost of production and distribution. 


$$
T C=P C+D C
$$

Four variables were used in the integrated problem we define as follows:

For all $1 \leq k, l \leq n$, if $b_{k}$ built, is equal to $w_{k}=1$ and otherwise is zero.

If $l$ isthe delivered shipment formed and $n=1_{\text {otherwise is zero. For all tasks }} 1 \leq j \leq n$ in this way we define a binary variable ${ }^{X} j k$ as follow that if the task $j_{\text {belongs to the category }}$ $d_{l}$ the amount is $z_{j l}=1$ and otherwise is zero value.As well as binary variable if the value of the shipment is delivered and otherwise is zero. It is assumed that they is $w_{0}=0, x_{j 0}=0$.

The concurrent planning of production and distribution issue based on Cheng, Leung and Lee [1] is defined as follows:

$$
\min \text { imize } T C=P C+D C
$$

Subject to:

$$
\begin{array}{ll}
T_{k}=\max \left\{t_{j} \mid x_{j k}=1\right\} & k=1, \ldots, n \\
C_{k}=C_{k-1}+T_{k} & k=1, \ldots, n \\
\sum_{k=1}^{n} x_{j k}=1 & j=1, \ldots, n \\
\sum_{j=1}^{n} x_{j k} S_{j} \leq B & k=1, \ldots, n \\
x_{j k} \leq w_{k} \quad j=1, \ldots, n & k=1, \ldots, n \\
\sum_{l=1}^{n} z_{j l}=1 & j=1, \ldots, n
\end{array}
$$




$$
\sum_{j=1}^{n} Z_{j l} s_{j} \leq G \quad l=1, \ldots, n
$$

$$
z_{j l} \leq y_{l} \quad j=1, \ldots, n \quad l=1, \ldots, n
$$

$$
L=\sum_{l=1}^{n} y_{l}
$$

$$
K=\sum_{k=1}^{n} w_{k}
$$

$$
P C=\sum_{k=1}^{n} T_{k}
$$

$$
D C=\delta L \quad \delta>0
$$

$$
C_{0}=T_{0}=w_{0}=x_{j 0}=0
$$

$$
w_{k}, y_{l}, x_{j k}, z_{j l} \in\{0,1\} \quad j=1, \ldots, n
$$

Limitation (1) shows the total cost of production and distribution, that each of them separately is in limitations 12 and 13 respectively. Limitation (2) shows the time for processing a bunch. Limitation 2 and 3 together suggest that the process of a batch is without interruption. Limitation (4) states that each work is exactly for the same category. Limitation (5) states that the overall size of tasks within a category does not exceed the capacity of the machine B. Limitation (6) states that if the amount of task ${ }^{x_{j k}}$ for task ${ }^{j}$ was equal to 1 then needs to be $w_{k}=1$. Limitation (7) states that each work exactly dedicated to one delivery. Limitation (8) states that restrictions the overall size of tasks within a delivery 
vehicle does not exceed the capacity. Limitation (9) states that If the amount of ${ }^{Z}{ }_{j l}$ was equal to 1 then it is $y_{l}=1$. Limitation 10 shows the number of non-empty deliveries. Limitation (15) shows the amount of binary variable. In the original article the amount of NP-hard has been proven.

\section{Genetic Algorithm}

In the previous episode, integrated production and distribution planning issue stated that to solve this issue the Genetic Algorithm was used. Genetic algorithms have been founded on the principles of natural evolution. This evolutionary algorithm has evolved over the generations. Over the generations, the purpose of improvement is the fitness of individuals. This improvement obtains by simulating the two main mechanisms that are based on Darwin's theory in the evolution of living organisms [23]:

- Selection: ensuring that people with higher fitness, have higher recreation function and survival.

- Recreation: permission of composition, procreation, and diversity of parents features to produce offspring with new features. The basic principles of genetic algorithms were presented by John Holland [24] in 1975. Later this method was developed by scientists such as Goldberg and Davis. Including done work in integrated timing and delivering issue with genetic algorithm approach can refer to the affairs of Hamidnia and colleagues [25] and a single machine timing issue and sending category with the objective function total earliness and tardiness, transportation costs and inventory were examined and stated a genetic algorithm to solve the problem. Turabi and colleagues [8] investigated integrated manufacturing and distribution supply chain as a single machine and the objective function to minimize the total costs of preparing; storing and sending studied and provided a hybrid genetic algorithm to solve the problem.

\subsection{The way to display the answer}

In a provided genetic algorithm to demonstrate a possible answer three sets of integers is considered. The filaments basically are chromosome and each section is strand genes. In the first chromosome, each gene is on represents task, actually the first chromosome represents the sequence of tasks and the second and third row shows the number of tasks within each category on the processing machine and the number of tasks available inside each delivery due to the sequence. The initial population generated randomly. In a way, that first line is created with a random permutation of the number of tasks and created the second and third rows with the creation of random numbers between 1 and the number of jobs and finally, each of the random numbers generated by the operator is correct-sol for possible modification of the population. For example, in Figure 1 an issue is shown with $n=5$.

It is noted that tasks 5 and 1 by the first category, and two tasks 2 and 3 by second task categories and tasks 4 by the third working category process on the machine. The third line indicates that the task 5 by, the first vehicle, 3,1 and 2 by the second vehicle and task 4 by 
the third vehicle are carried. On the other hand, if the answer is acceptable if the size of the work and tasks within each category be less than the vehicle capacity car that the answer is that chromosomes feasibility correct-sol amended by the operator.

\begin{tabular}{|l|l|l|l|l|}
\hline 5 & 1 & 3 & 2 & 4 \\
\hline 2 & 2 & 1 & 3 & 4 \\
\hline 1 & 3 & 1 & 4 & 1 \\
\hline
\end{tabular}

Figure 1. displays the answer

\section{2 correct-sol operator}

By changing the randomly generated numbers in the second and third row the tasks allocated to groups of delivery and processing machine that categories capacity does not exceed the capacity of the machine or vehicle. The working method is in a way that for example, in Figures 2 to 4 to assign tasks to categories of processing first two tasks 5 and 1 allocate to the first category If the size of the portfolio exceeded the capacity of the machine they leave the task to assign it to the second category and with tasks 3 and 2 locate in the second category again, if the size of the portfolio exceeded the capacity of the machine with sequence the tasks assigned to the transition to the third category and the second row numbers until assigning all tasks corrected to the processing categories and the remaining numbers remain the same genes in the second row. This operator works in a similar way to the third row until created answer become possible.

\begin{tabular}{|l|l|l|l|l|}
\hline 5 & 1 & 3 & 2 & 4 \\
\hline 2 & 2 & 1 & 3 & 4 \\
\hline 1 & 3 & 1 & 4 & 1 \\
\hline
\end{tabular}

Figure 2. The initial answer

\begin{tabular}{|l|l|l|l|l|}
\hline 5 & 1 & 3 & 2 & 4 \\
\hline 1 & 3 & 1 & 3 & 4 \\
\hline 1 & 3 & 1 & 4 & 1 \\
\hline
\end{tabular}

Figure 3. Modified initial response by the operator correct-sol

\begin{tabular}{|l|l|l|l|l|}
\hline 5 & 1 & 3 & 2 & 4 \\
\hline 1 & 3 & 1 & 3 & 4 \\
\hline 1 & 3 & 1 & 4 & 1 \\
\hline
\end{tabular}

Figure 4. Readjustment initial responses (Figure 2) by the operator correct-sol 


\section{Macrothink}

Selection is the first action that applies to the population. At this stage, the number of chromosomes can be selected from the population as a parent. Among the most common methods include roulette wheel selection, competition, random and ranking. In the proposed genetic algorithm roulette wheel method is used. The selection probability proportional to their fitness function is variable.

\subsection{Single-point intersection Operator}

After all the solutions of the initial population become feasible to produce new answers the intersection at a rate of 0.7 is used. The operator is in a way that first considers two parents randomly. For example, the first random row number 0.7 a random number corresponding to the second and third row and consider 0.7 to 0.15 and respectively and the number generated randomly If this number is between 0 and 0.7 in the first row and if is 0.7 to 0.85 the third $r$ the third row is selected to perform the intersection. Now suppose the random number generated is equal to 0.75 and the second row has been selected for the intersection, the number randomly selected between 1 and n-1 For example, the number 2 places in the second row of the first parent homes and homes placed third to (n) the second parent and achieved first child. This process is shown in Figures 5 to 7 and place in the second child of 1 and 2 homes and homes 3 placed to the first parent and the remaining rows will stay the same.

\begin{tabular}{|l|l|l|l|l|}
\hline 5 & 1 & 3 & 2 & 4 \\
\hline 2 & 2 & 2 & 3 & 4 \\
\hline 1 & 3 & 1 & 4 & 1 \\
\hline
\end{tabular}

Figure 5. The first parent

\begin{tabular}{|l|l|l|l|l|}
\hline 4 & 3 & 1 & 5 & 2 \\
\hline 3 & 1 & 3 & 2 & 4 \\
\hline 1 & 2 & 1 & 1 & 1 \\
\hline
\end{tabular}

Figure 6. The second parent

\begin{tabular}{lll|l|}
$22 \mid 134$ & $31 \mid$ & $31 \mid 123$ \\
$31 \mid 324$ & $32 \mid$ & $32 \mid 324$
\end{tabular}

Figure 7. Intersection operator

1. The choice of the second row of the second gene as a single point of failure

2. in a placeof Genes in two chromosomes

3. Insertion of gene with the previous sequence 


\section{The two-point intersection operator}

In this operator selected the intersection of two points of the first and second parent and given the range of randomly generated number by the intersection of the row is selected for practice. Every selected parent with selecting two points is divided into three parts to create the first child in the middle of the second parent is the first parent insertion and to create a second child is placed in the middle of the first parent in the second parent. In Figure 8, the first and second parent choice and midpoints displacement are shown

$$
\begin{array}{l|l|l|lllll}
2|21| 34 & 2 & 1 & 3 & 3 & 4 \\
3 & 13 & 24 & 3 & 2 & 1 & 2 & 4
\end{array}
$$

Figure 8. Two-point intersection operator

\section{6 mutation operation}

For operations mutations in the genetic algorithm, one parent is required. In the mutations proposed algorithm to two randomly selected two genes in a chromosome and displacement values on the Genes or a random selection of a gene on chromosome reverse arrangement of genes on the same chromosome and is then shown to be the case in Figure 9. Row gene selection and mutation is generated to operations due to the range of random number.

$$
22 \mid \begin{array}{llllll}
134 & 2 & 2 & 4 & 3 & 1
\end{array}
$$

Figure 9. mutation operator

\section{6 algorithm termination condition}

At the end of iteration a certain number of Best Answer selected and by operator roulette wheel according to the fitness function in the next iteration to the next iteration is used as the parent and the initial population. The proviso of end algorithms of the proposed genetic is defined to achieve to the determined number of generations.

\section{The calculations of number}

To solve this version the software 24.1.2 GAMS and 2014 MATLAB software is used to solve the meta-heuristic model. In order to test the performance of algorithm design example and the results have been reported Genetics 12 levels. In each case, there are three parameters of 'number of tasks-size of tasks-time of task processing. The numbers of tasks are shown with $J 1, J 2, J 3$ which represent 20,10 , and 30 of tasks. The size of the portfolio in three levels is representing the size of tasks in the intervals $[30,1],[20,1]$ and $[1,10]$. The tome of processing is divided into two levels. Processing time intervals that represent portfolio in 20 and 1] and [1, 10], respectively. Examples issue from left to right as "the number of tasks-time processing tasks-things" is displayed. Examples are given in Table 1. 
Table 1. Examples

\begin{tabular}{|c|c|c|c|c|c|c|c|c|}
\hline \multirow{2}{*}{$\begin{array}{c}\text { Para } \\
\text { meter } \\
\text { s }\end{array}$} & \multicolumn{3}{|c|}{$\begin{array}{c}\text { the numbers } \\
\text { of tasks }\end{array}$} & \multicolumn{2}{|c|}{$\begin{array}{l}\text { The size of } \\
\text { tasks }\end{array}$} & \multicolumn{3}{|c|}{$\begin{array}{c}\text { The processing time of } \\
\text { tasks }\end{array}$} \\
\hline & $J_{\backslash}$ & $J \zeta$ & $\mathrm{J} r$ & S) & $S_{r}$ & $T_{1}$ & Tr & $\mathrm{T}^{\mu}$ \\
\hline $\begin{array}{c}\text { amou } \\
\text { nt }\end{array}$ & 1. & $r$. & r. & $\begin{array}{l}91 \cdot] \\
{[1}\end{array}$ & 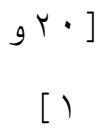 & $\begin{array}{l}91 \cdot] \\
{[1}\end{array}$ & 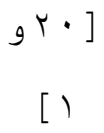 & $\begin{array}{l}g r \cdot] \\
{[1}\end{array}$ \\
\hline
\end{tabular}

The problem answers are compared and the results are shown in Tables 2 and 3, the dimensions of the problem with the number of things that GAMS algorithm is not able to resolve the issue at the time of 3600 seconds Genetic Algorithm nearly optimum response and shorter time to lose.

Table 2. Computational results J2

\begin{tabular}{|c|c|c|c|c|}
\hline $\begin{array}{c}\delta=0 / 5 \\
B=G=40\end{array}$ & \multicolumn{2}{|c|}{ GAMS } & \multicolumn{2}{|c|}{ GENETIC } \\
\hline sample & $\begin{array}{l}\text { The objective } \\
\text { function }\end{array}$ & $\begin{array}{c}\text { Time } \\
\text { ( second ) }\end{array}$ & $\begin{array}{l}\text { The objective } \\
\text { function }\end{array}$ & $\begin{array}{c}\text { Time } \\
\text { (second) }\end{array}$ \\
\hline J2 S1 T1 & 20.5 & 0.699 & 20.5 & 9 \\
\hline $\mathrm{J} 2 \mathrm{~S} 1 \mathrm{~T} 2$ & 40.5 & 1.067 & 40.5 & 9.17 \\
\hline J2 S1 T3 & 60.5 & 1 & 61.5 & 8.94 \\
\hline J2 S2 T1 & 31.5 & 4.43 & 33.5 & 108 \\
\hline $\mathrm{J} 2 \mathrm{~S} 2 \mathrm{~T} 2$ & 57.5 & 10.036 & 58 & 78.48 \\
\hline $\mathrm{J} 2 \mathrm{~S} 2 \mathrm{~T} 3$ & 78.5 & 7 & 84.5 & 89.84 \\
\hline
\end{tabular}


Table 2. Computational results J3

\begin{tabular}{|c|c|c|c|c|}
\hline $\begin{array}{c}\delta=0 / 5 \\
B=G=40\end{array}$ & \multicolumn{2}{|c|}{ GAMS } & \multicolumn{2}{|c|}{ GENETIC } \\
\hline Sample & $\begin{array}{l}\text { The objective } \\
\text { function }\end{array}$ & $\begin{array}{c}\text { Time } \\
\text { ( second) }\end{array}$ & $\begin{array}{l}\text { The objective } \\
\text { function }\end{array}$ & $\begin{array}{c}\text { Time } \\
\text { ( second })\end{array}$ \\
\hline J3 S1 T1 & 30.5 & 369 & 40 & 91 \\
\hline J3 S1 T2 & 57.7 & 93.386 & 44 & 98.51 \\
\hline J3 S1 T3 & 77.5 & 134.579 & 94 & 91 \\
\hline J3 S2 T1 & 32.47 & 1346.223 & 58.5 & 141 \\
\hline J3 S2 T2 & 90.72 & After 3600 & 136.5 & 143 \\
\hline J3 S2 T3 & & $\begin{array}{l}\text { Seconds to did } \\
\text { not reach to } \\
\text { answer }\end{array}$ & & \\
\hline J3 S1 T1 & & & & \\
\hline J3 S1 T2 & 109.76 & 1937 & 441 & 142 \\
\hline
\end{tabular}

\section{Conclusion}

Due to the discrete nature of the intended using of methods for solving discrete issues such as the ant colony algorithm is proposed. It is proposed to improve the model to models with two different objective functions considered the cost of production and delivery cost and it will be resolved bi-objective function.

\section{References}

Agnetis, A., Aloulou, M. A., \& Fu, L. (2014). Coordination of production and interstage batch delivery with outsourced distribution. European Journal of Operational Research, 338, 130-142. https://doi.org/10.1016/j.ejor.2014.03.039

Averbakh, I., \& Xue, Z. (2007). On-line supply chain scheduling problems with preemption. European Journal of Operational Research, 181(1), 500-504. https://doi.org/10.1016/j.ejor.2006.06.004

Ba-Yi Cheng, Joseph Y. T., \& Leung Kai Li. (2015). Integrated scheduling of production and distribution to minimize total cost using an improved ant colony optimization method. Computers \& Industrial Engineering, 83, 217-225. https://doi.org/10.1016/j.cie.2015.02.017

Carter, C. B., \& Norton, M. G. (2013). Ceramic Materials: Science and engineering (2nd ed.). Springer. https://doi.org/10.1007/978-1-4614-3523-5 
Chen, Z. L., \& Hall, N. G. (2007). Supply chain scheduling: Conflict and cooperation in assembly systems. Operation Research, 55(6), 1072-1089. https://doi.org/10.1287/opre.1070.0412

Chen, Z. L., \& Vairaktarakis, G. L. (2005). Integrated scheduling of production and distribution operations. Management Science, 51(4), 614-628. https://doi.org/10.1287/mnsc.1040.0325

Cheng, B., Wang, Q., Yang. S., \& Hu, X. (2013). An improved ant colony optimization for scheduling identical parallel batching machines with arbitrary job sizes. Applied Soft Computing, 13(2), 765-772. https://doi.org/10.1016/j.asoc.2012.10.021

Demodaran, P., Manjeshwar, P. K., \& Srihari, K. (2006). Minimizing make span on a batch-processing machine with arbitrary job sizes using genetic algorithm. International Journal of production Economics, 103(2), 882-891.

Hamidnia, A., Khakabimamaghani, S., Mazdeh, M. M., \& Jafari, M. (2012). A genetic algorithm for minimizing earliness/tardiness penalties with distinct due dates and batch delivery considerations. Advanced Intelligent Computing, Springer, pp. 139-146.

Holland, J. H. (1975). Adaptation in natural and artificial systems an introductory analysis with applications to biology, control, and artificial intelligence. U Michigan Press.

Jula, P., \& Leachman R. C. (2010). Coordinated multistage scheduling of parallel batch-processing machines under multi-resource constraints. Operations Research, 58(4), 933-947. https://doi.org/10.1287/opre.1090.0788

Kashan, A. H., Karimi, B., \& Ghomi, F. (2009). A note on minimizing make span on a single batch-processing machine with nonidentical job sizes. Theoretical Computers Science, 410(27-29), 2754-2758. https://doi.org/10.1016/j.tcs.2009.02.014

Kashan, A. H., Karimi, B., \& Jenabi, M. (2008). A hybrid genetic heuristic for scheduling parallel batch-processing machines with arbitrary job sizes. Computer \& Operations Research, 35(4), 1084-1098. https://doi.org/10.1016/j.cor.2006.07.005

Koh, S. G., Koo, P. H., Kim, D. C., \& Hur, W. S. (2005). Scheduling a single batch-processing machine with arbitrary job sizes and incompatible job families. International Journal of Production Economics, 98(1), 81-96. https://doi.org/10.1016/j.ijpe.2004.10.001

Li, S. G., Lio, G. J., Wang, X. L. \& Liu, Q. M. (3005). Minimizing make span on a single batching machine with release times and non-identical job sizes. Operations Research Letters, 33(2), 157-164. https://doi.org/10.1016/j.orl.2004.04.009

Melouk, S., Demodaran, P., \& Chang, P. Y. (2004). Minimizing make span for single machine batch-processing with arbitrary job sizes using simulated annealing. International Journal of Production Economics, 87(2), 141-147. https://doi.org/10.1016/S0925-5273(03)00092-6 


\section{Macrothink}

Journal of Management Research

ISSN 1941-899X

2017, Vol. 9, No. 1

Naso, D., Surico, M., Turchaiano, B., \& Kaymak, U. (2007). Genetic algorithms for supply-chain scheduling: A case study in the distribution of ready-mixed concrete. European $\begin{array}{llll}\text { Journal of } & \text { Operational } & \text { Research, 2069-2099. }\end{array}$ https://doi.org/10.1016/j.ejor.2005.12.019

Petrowski, A., \& Taillard, E. (2006). Metaheuristics for hard optimization. Springer.

Sawik, T. (2009). Coordinated supply chain scheduling. International Journal of Production Economics, 120(2), 437-451. https://doi.org/10.1016/j.ijpe.2008.08.059

Selvarajah, E., \& Steiner, G. (2009). Approximation algorithms for the supplier's supply chain scheduling problem to minimize delivery an inventory holding costs. Operations Research, 57(2), 426-438. https://doi.org/10.1287/opre.1080.0622

Sevaux, M., \& Peres, S. D. (2003). Genetic algorithms to minimize the weighted number of late jobs on a single machine. European Journal of Operational Research, 151(2), 296-306. https://doi.org/10.1016/S0377-2217(02)00827-5

Torabi, S. A., Ghomi, S. M. T., \& Karimi, B. (2006). A hybrid genetic algorithm for the finite horizon economic lot and delivery scheduling in supply chains. European Journal of operational Research, 173(1), 173-189. https://doi.org/10.1016/j.ejor.2004.11.012

Uzsoy, R. (1994). Scheduling a single batch processing machine with non- identical job sizes. International Journal of Production Research, 32(7), 1615-1635. https://doi.org/10.1080/00207549408957026

Yimer, A. D., \& Demirli, K. (2010). A genetic approach to two-phase optimization of dynamic supply chain scheduling. Computers \& Industrial Engineering, 58(3), 411-423. https://doi.org/10.1016/j.cie.2009.01.010

Zdgordi, S. H., Abadi, I. N. K., \& Nia, M. A. B. (2007). A novel genetic algorithm for solving production and transportation scheduling in a two-stage supply chain. Computers \& Industrial Engineering, 58(3), 373-381. https://doi.org/10.1016/j.cie.2009.06.012 